\title{
Neoantigen-loaded Autologous Dendritic Cell Vaccine
}

National Cancer Institute

\section{Source}

National Cancer Institute. Neoantigen-loaded Autologous Dendritic Cell Vaccine. NCI

Thesaurus. Code C141422.

A personalized, peptide-based therapeutic dendritic cell (DC) vaccine consisting of autologous DCs loaded with immunogenic peptides derived from autologous cancer cells, with potential immunomodulating and antineoplastic activities. Upon leukapheresis, mature DCs are loaded with immunogenic neoantigens. Vaccination with the neoantigenloaded autologous DC vaccine stimulates the host immune system to mount a cytotoxic T-lymphocyte (CTL) response against tumor cells expressing the neoantigens, which results in tumor cell lysis. 